\title{
Pelatihan Karakter Building Dan Mental Imagery Bagi Atlit PPLP Sumatera Barat
}

\author{
Nurul Ihsan', Syahrastani' ${ }^{2}$, Ali Asmi $^{3}$ \\ Jurusan Pendidikan Olahraga, Fakultas Ilmu Keolahragaan, Universitas Negeri Padang \\ Email: nurulihsan@ fik.unp.ac.id, syahrastani@ fik.unp.ac.id, aliasmi@ fik.unp.ac.id
}

\begin{abstract}
Character is a process that is continuously carried out to form, character, character, and mental characteristics that are based on the spirit of devotion and togetherness. Fostering characters that display conducive characters in social, national and state life based on the values of the Pancasila philosophy. Mental image is the ability of humans to imagine images in the mind after the original stimuli can no longe $r$ be seen.

This cognitive component is one of the ways that help factors in existing memories and thoughts. This component provides explanations to help translate the concepts introduced. Every athlete is always confronted with a variety of discussions about achievement, but not all talks and related achievements are supported by various factors not only technical and physical but also the character and mental. This is intended so that everyone has a strong character and also has a good mentality when competing. However, not all athletes have this, so the re is a need to develop character and mental training for the athletes that are needed to be used to improve athlete performance.
\end{abstract}

Keywords: Silat Character, Pancasila Philosophy, Mental Imagery, Athlete

Achievement, Psychological Characte r

Abstak

Karakter merupakan suatu proses yang terus menerus di lakukan untuk me mbentuk, tabiat, watak, dan sifat-sifat kejiwaan yang berlandaskan kepada semangat pengabdian dan kebersamaan. Membina karakter yang ada sehingga menampilkan karakter yang kondusif dalam kehidupan bermasyarakat, berbangsa dan be megara yang dilandasi dengan nilai - nilai falsafah Pancasila. Mental imagery adalah kemampuan manusia untuk mengkhayalkan gambaran-gambaran di dalam pikiran setelah stimuli asli adalah tidak dapat dilihat lagi.

Komponen kognitif ini adalah salah satu cara yang me mbantu faktor-faktor di dalam memori-memori dan pemikiran yang ada. Komponen ini menyediakan dengan gambaran-gambaran untuk bantuan menerjemahkan konsep-konsep yang diperkenalkan. Setiap atlit, selalu dihadapkan dengan berbagai persoalan mengenai prestasi, akan tetapi tidak semua pelatih dan unsur te rkait me nyadari bahwa prestasi juga didukung oleh berbagai faktor bukan hanya teknik dan fisik saja tapi juga karakter dan mental. Hal ini bertujuan agar setiap atlit itu memiliki karakter yang kuat dan baik serta memiliki mental yang baik terutama saat bertanding. Akan

12 | Pelati han Karakter Buil ding Dan Mental Imagery

Nurul Ihsan ${ }^{1}$, Syahrastani $^{2}$, Ali As mi ${ }^{3}$ 
tetapi, tidak semua atlit memiliki hal tersebut sehingga perlu adanya pelatihan pembangunan karakter dan mental bagi atlit yang nantinya diharapkan dapat dimanfaatkan bagi peningkatan prestasi atlit.

Kata Kunci: Karakter Silat, Falsafah Pancasila, Mental Imagery, Prestasi Atlet, Sifat Kejiwaan

\section{ANALISIS SITUASI}

Indonesia merupakan salah satu negara berkembang yang sedang giat-giatnya melaksanakan pembangunan di segala bidang. Salah satu bidang yang tidak kalah penting adalah pembangunan dalam bidang olahraga. Olahraga kini telah mengalami kemajuan yang sangat pesat dimana saat ini olahraga telah memasuki semua aspek kehidupan seperti industri, perekonomian, pendidikan dan lain sebagainya. Hal ini sesuai dengan UndangUndang Republik Indonesia No.3 Tahun 2005 Tentang Sistem Keolahragaan Nasional Pasal 4 yang menyatakan bahwa keolahragaan nasional bertujuan untuk memelihara dan meningkatkan kesegaran dan kebugaran jasmani, prestasi, kualitas manusia, menanamkan nilai moral dan akhlak mulia, sportivitas, disiplin, mempererat dan membina persatuan dan kesatuan bangsa, memperkukuh ketahanan nasional, serta mengangkat harkat, martabat, dan kehormatan bangsa.

Berdasarkan kutipan di atas, dapat diketahui bahwa salah satu tujuan yang ingin dicapai oleh bangsa Indonesia adalah memelihara dan meningkatkan prestasi-prestasi di berbagai cabang olahraga. Selain itu, tercapainya tujuan keolahragaan nasional yaitu menumbuhkan generasi yang sehat jasmani maupun rohani, memiliki kebugaran jasmani, berkualitas, bermoral dan akhlak mulia, sportif, dan disiplin yang nantinya diharapkan akan berdampak positif terhadap pembangunan nasional di bidang-bidang lainnya. Agar hal tersebut dapat terwujud, maka dibutuhkan sekali kerjasama antara semua pihak baik pemerintah, insan olahraga maupun masyarakat.

Keadaan seperti ini bukan hanya menjadi tanggung jawab Pemerintah saja, akan tetapi sudah seharusnya menjadi tanggung jawab kita semua sebagai warga negara Indonesia. Pemerintah sebagai penangung jawab utama pada saat ini telah melakukan berbagai usaha diantaranya telah mendirikan Pusat Pendidikan dan Latihan Pelajar (PPLP) diberbagai daerah di Indonesia. Salah satu daerah yang juga mendirikan PPLP adalah Sumatera Barat.

\section{3 | Pelatihan Karakter Buil ding Dan Mental Imagery} Nurul Ihsan ${ }^{1}$, Syahrastani $^{2}$, Ali As mi ${ }^{3}$ 


\section{JURNAL BERKARYA PENGABDIAN PADA MASYALTAKZAJ \\ Volume 1, No.1, 2019 \\ ISSN — (Print) I -

Open Access | http:jba.ppj.unp.acild

Saat ini di PPLP Sumatera Barat para atlitnya berasal dari berbagai pelajar yang berprestasi yang berasal dari berbagai daerah di Sumatera Barat. Oleh sebab itu PPLP Sumatera Barat itu dapat dianggap sebagai tolak ukur prestasi olaharga pelajar Sumatera Barat. Akan tetapi, pada saat POPNAS yang terakhir prestasi para kontingen Sumatera Barat yang merupakan para atlit yang berasal dari PPLP masih kurang memuaskan. Hal ini disebabkan berbagai faktor diantaranya adalah status gizi, kondisi fisik dan motivai. Hal ini sesuai dengan Syafruddin (2011:22) yang menyatakan bahwa, "kemampuan seorang atlit pada saat kompetisi dipengaruhi oleh faktor kondisi fisik, teknik, taktik dan mental”. Akan tetapi semua faktor tersebut juga harus didukung oleh faktor lainnya yait karakter dan mental yang dimiliki atlit agar dapat berprestasi.

Karakter merupakan suatu proses yang terus menerus di lakukan untuk membentuk, tabiat, watak, dan sifat-sifat kejiwaan yang berlandaskan kepada semangat pengabdian dan kebersamaan. Menyempurnkan karakter yang ada untuk terwujudnya karakter yang diharapkan dalam rangka penyelenggaraan pemerintahan dan pelaksanaan pembangunan. Membina karakter yang ada sehingga menampilkan karakter yang kondusif dalam kehidupan bermasyarakat, berbangsa dan bernegara yang dilandasi dengan nilai - nilai falsafah Pancasila.

Mental imagery adalah kemampuan manusia untuk mengkhayalkan gambarangambaran di dalam pikiran setelah stimuli asli adalah tidak dapat dilihat lagi. Komponen kognitif ini adalah salah satu cara yang membantu faktor-faktor di dalam memori-memori dan pemikiran yang ada. Komponen ini menyediakan dengan gambaran-gambaran untuk bantuan menerjemahkan konsep-konsep yang diperkenalkan. Mental imagery menggambarkan suatu hasil tertentu sebelum hasil tersebut dicapai. Dengan visualisasi seseorang seolah-olah membuat rancangan gambar secara abstrak tentang hasil yang ingin dicapai. Mental imagery merupakan kemampuan manusia untuk menggambarkan kesan dalam pikiran sesudah stimuli original pada pandangan keluar.

Karakter dan mental yang baik harus dimiliki oleh seorang atlit yang berprestasi. Hal ini karena dalam pembinaan prestasi juga harus didukung dengan pembinaan karakter dan mental atlit. Karakter dan mental tersebut harus selalu dibangun dan dilatih bagi peningkatan prestasi atlit. Akan tetapi, masih ada atlit yang memiliki karakter dan mental yang kurang baik sehingga perlu dilatih dan ditingkatkan.

\section{4 | Pelatihan Karakter Buil ding Dan Mental Imagery Nurul Ihsan ${ }^{1}$, Syahrastani ${ }^{2}$, Ali As mi ${ }^{3}$}




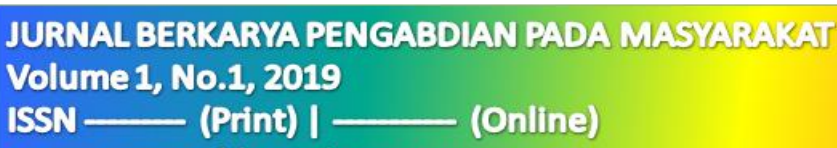

Open Access | http:jba.ppj.unp.acild

Dari beberapa hasil temuan di atas secara umum pengetahuan dan kemampuan atlit terhadap karakter dan mental masih kurang. Melihat kondisi yang demikian perlu dilakukan pembinaan tentang pemahaman dan pelatihan terhadap karakter dan mental bagi atlit. Untuk mewujudkan harapan tersebut, lembaga pengabdian kepada masyarakat Universitas Negeri Padang (LPM-UNP) melalui tim staf pengajarnya yang telah melakukan kerja sama dengan PPLP Provinsi Sumatera Barat, rencananya akan dilakukan penyuluhan dan pelatihan pembangunan karakter dan mental imagery bagi atlit PPLP Sumatera Barat.

\section{SOLUSI DAN TARGET}

Karakter sebagai tabiat, watak, sifat-sifat kejiwaan, akhlak atau budi pekerti merupakan hal yang sangat penting dalam kehidupan berorganisasi, baik organisai pemmerintahan maupun organisasi swadaya/usaha dan lain sebagainya. Dapat dikatakan bahwa karakter manusia Indonesia dalam kehidupan bermasyarakat, berbangsa dan bernegara merupakan kunci yang sangat penting untuk mewujudkan cita-cita perjuangan guna terwjudnya masyarakat adil dan makmur berlandaskan Pancasila.

Mengiingat karakter suatu masyarakat, bangsa dan negara mempunyai nilai dan makna yang sangat strategis, maka faktor-faktor yang perlu dan senantia diperhatiakan antara lain; Ideologi, Politik, Ekonomi, Sosial Budaya, Agama, Normatif (Hukum dan peraturan perundangan), Pendidikan, Lingkungan, dan Kepemimpinan. Berkenaan dengan hal tersebut pembangunan pendidikan karakter merupakan tumpuan untuk menjamin perpaduan dari ketiga lapisan di atas dapat berjalan selaras dengan zaman. Di era global saat ini, kreativitas dan inovasi dihargai sangat tinggi melebihi sumber daya alam.

Kreativitas dan inovasi yang dibarengi dengan kemampuan mengelola jaringan merupakan kunci dari keunggulan suatu bangsa. Situasi ini hanya dapat terwujud bila ketiga lapis pendidikan karakter yaitu kreativitas dan inovasi dalam bidang keilmuan, kemampuan mengelola jaringan berupa sikap memuliakan sesama makhluk Tuhan, dan kecintaan serta bangga terhadap bangsanya dilaksanakan dengan harmonis dan konsisten.

15 | Pelati han Karakter Building Dan Mental Imagery Nurul Ihsan ${ }^{1}$, Syahrastani ${ }^{2}$, Ali As mi ${ }^{3}$ 


\section{METODE PELAKSANAAN}

\section{Tempat dan Waktu Pelaksaan}

PPLP Sumatera Barat dan Pelaksaan kegiatan ini dilaksanakan selama 6 bulan mulai sejak proposal ini disetujui. Rencana jadwal dan kegiatan di sajikan dalam lampiran proposal ini.

Tabel.

JADWAL KEGIATAN

\begin{tabular}{|c|c|c|c|c|c|c|c|c|}
\hline \multirow{2}{*}{ No } & \multirow{2}{*}{\multicolumn{2}{|c|}{ Tahap Kegiatan }} & \multicolumn{6}{|c|}{ Bulan } \\
\hline & & & 6 & 7 & 8 & 9 & 10 & 11 \\
\hline \multirow[t]{4}{*}{1} & \multirow[t]{4}{*}{ Persiapan } & Pengurusan kerjasama dan izin turun & & & & & & \\
\hline & & Kelapangan & & & & & & \\
\hline & & Pengadaan bahan penyuluhan dan & & & & & & \\
\hline & & Pelatihan & & & & & & \\
\hline \multirow[t]{3}{*}{2} & \multirow[t]{3}{*}{ Pelaksanaan } & Mengadakan penyuluhan & & & & & & \\
\hline & & Mempraktekkan hasil pelatihan dan & & & & & & \\
\hline & & Melakukan evaluasi & & & & & & \\
\hline \multirow[t]{2}{*}{3} & \multirow[t]{2}{*}{ Pelaporan } & Menyusun draft laporan & & & & & & \\
\hline & & $\begin{array}{l}\text { Menyusun laporan akhir dan } \\
\text { publikasi }\end{array}$ & & & & & & \\
\hline
\end{tabular}

\section{Khalayak Sasaran}

Ada beberapa target dan luaran yang dapat diambil dari hasil pelaksanaan kegiatan ini, antara lain sebagai berikut:

1. Para atlit mampu melakukan pembangunan karater dan mental imagery.

2. Para atlit mampu memahami dan melaksanakan pembangunan karater dan mental imagery.

3. Para atlit mampu memahami bagaimana implikasi dari pembangunan karater dan mental imagery dalam olahraga sehingga dapat memberikan pengaruh positif terhadap prestasi atlit.

Hasil pelatihan ini hendaknya menjadikan para atlit di PPLP Sumatera Barat mengerti dan memahami bagaimana melakukan pembangunan karater dan mental imagery.

\section{Metode Pengabdian}

Untuk mengatasi permasalahan dalam pembangunan karater dan mental imagery maka diberikan solusi yaitu sebagai berikut:

\section{6 | Pelatihan Karakter Buil ding Dan Mental Imagery Nurul Ihsan ${ }^{1}$, Syahrastani ${ }^{2}$, Ali As mi ${ }^{3}$}


1. Metode ceramah dalam penyampaian pembangunan karater dan mental imagery dalam olahraga.

2. Metode demonstrasi untuk pertolongan dalam pembangunan karater dan mental imagery dalam olahraga bagi atlit.

Kegiatan pengabdian kepada masyarakat ini terkait dengan LPM Universitas Negeri Padang dan Fakultas Ilmu Keolahragaan Universitas Negeri Padang serta PPLP Sumatera Barat.

\section{Indikator Kebe rhasilan}

Dikatakan penting karena karakter mempunyai makna atau nilai yang sangat mendasar untuk mempengaruhi segenap pikiran, tindakan dan perbuatan setiap insan manusia dalam kehidupan bermasyarakat, berbangsa dan bernegara. Nilai yang dimaksud adalah; Kejuangan, Semangat, Kebersamaan atau Gotong royong, Kepedulian atau solider, sopan santun, Persatuan dan kesatuan, Kekeluargaan, dan Tanggung Jawab.

Nilai-nilai seperti ini tampaknya cenderung semakin luntur dalam kehidupan berbangsa di Negara Kesatuan Republik Indonesia. Hal ini dapat dilihat secara jelas bahwa misalnya berbagai kasus konflik sosial dan komunal yang marak terjadi di berbagai daerah dengan penyebab yang sepele.

Menanamkan nilai dan prinsip moral, sebagai panduan etika, serta meningkatkan komitmen setiap individu untuk menjalankannya. Memberikan makna bekerja kepada setiap individu sehingga meningkatkan loyalitas dan juga produktivitas. Mampu menemukan kebahagiaan spiritual sehingga memandang pekerjaan bukan beban melainkan sebuah pengabdian dan panggilan jiwa (vocation/calling).

\section{Metode Evaluasi}

Evaluasi yang digunakan yaitu evaluasi proses dilaksanakan selama kegiatan pelatihan berlangsung yang menyangkut: wawasan tentang pembangunan karater dan mental imagery dalam olahraga.

a. Melalui kegiatan ini diharapkan bermanfaat bagi atlit dalam meningkatkan kemampuan dalam pembangunan karater dan mental imagery.

b. Melalui kegiatan ini diharapkan mampu memberikan pemahaman pentingnya pembangunan karater dan mental imagery bagi atlit.

17 | Pelatihan Karakter Building Dan Mental Imagery Nurul Ihsan ${ }^{1}$, Syahrastani ${ }^{2}$, Ali As mi ${ }^{3}$ 


\section{JURNAL BERKARYA PENGABDIAN PADA MASYALIHZZAIJ \\ Volume 1, No.1, 2019 \\ ISSN — (Print) I

Open Access | http:jba.ppj.unp.acild

c. Selain itu diharapkan out put dari kegiatan ini adalah atlit mampu mengaplikasikan dalam usaha meningkatkan prestasi.

\section{HASIL DAN PEMBAHASAN}

Penggambaran mental merupakan aspek keseharian dari pengalaman individu sedikit individu yang menyatakan bahwa dirinya jarang atau bahkan tidak pernah secara sadar mengalami penggambaran mental. Bagi mayoritas individu hal ini merupakan karakteristik umum terkait dengan pengalaman yang terjadi di pikiran. Bahasa pun menyajikan kosa kata terkait dengan pengalaman ini, seperti; 'visualisasi', 'melihat melalui mata mental', 'mendapatkan gambar di pikiran', 'pengambaran', 'melihat gambaran mental' dan lainnya.

Sangat sedikit jumlah mekanisme yang membahas mengenai fenomena serupa penggambaran pada modus sensorik lainnya, dan terdapat sedikit keraguan apakah hal tersebut dapat terjadi. Pengalaman serupa-penggambaran melalui modus sensorik selain visual sering dinyatakan sebagai 'pembayangan' (imagining) seperti sensasi rasa, aroma atau rasa pengecapan. Secara alternatif, karakteristik serupa-perseptual (quasi-perceptual) terhadap pengalaman perseptual dapat dinyatakan menggunakan bahasa sensorik yang berpadanan, contohnya 'melihat', 'mendengar', 'merasakan' atau yang lainnya.

Terlepas dari familiaritas dalam pengalaman, arti sesungguhnya dari ekspresi 'penggambaran mental' (mental imagery) relatif sulit untuk dinyatakan secara definitif dan perbedaan pemahaman terkait hal ini sering kali menambah kerancuan yang telah ada pada perdebatan panjang dan kompleks di kalangan filusuf, psikolog, dan ilmuwan bidang kognitif lainnya mengenai karakteristik dari penggambaran yang terjadi, fungsi psikologisnya (jika ada), bahkan pada keberadaannya penggambaran itu sendiri.

Proses belajar teknik tidak boleh terhenti-henti (terputus-putus) dalam waktu yang lama antara setiap satuan latihan, karena dapat mengurangi efekitifitas latihan. Dengan demikian latihan tekhnik yang baik itu adalah latihan yang dilakukan secara terus menerus tanpa terputus-putus sehingga akan menciptakan otomatisasi pada setiap gerakan yang dilakukan (Asnaldi, 2016). Pada literatur filosofis dan ilmiah, ekspresi dari 'penggambaran mental' digunakan pada berbagai hal berikut (sering kali dinyatakan secara eksplisit):

18 | Pelati han Karakter Buil ding Dan Mental Imagery Nurul Ihsan ${ }^{1}$, Syahrastani ${ }^{2}$, Ali As mi ${ }^{3}$ 
(1) Pengalaman sadar yang serupa-peseptual

(2) Representasi menyerupai gambar yang bersifat hipotesis di pikiran dan/atau di otak yang memunculkan hal (1)

(3) Representasi internal dari berbagai jenis (menyerupai gambar atau lainnya) yang secara langsung memunculkan hal (1)

Telah banyak diskusi terkait dengan penggambaran mental visual yang gagal memberikan perbedaan definitif antara keyakinan bahwa individu memiliki pengalaman serupa-visual (quasi-visual) dan keyakinan bahwa pengalaman tersebut perlu dijelaskan dengan keberadaan representasi di pikiran atau di otak, yang mana pada beberapa aspek dapat menyerupai gambar. Teori gambar (pictorial theory) mengenai penggambaran secara mendalam terpatri dalam bahasa dan psikologi populer.

Bahkan kota kata 'image' (bentukan dasar dari 'imagine', 'imagining') menyiratkan keberadaan gambar. Walaupun mayoritas dari individu dan para pakar kemungkinan tetap terus menerima sebagian dari teori gambar, banyak filusuf dan psikolog dari abad ke-20, dengan berbagai latar belakang teori, berargumen menentang hal tersebut. Bahkan pada beberapa kasus, mereka telah mengembangkan alternatif lain yang cukup mendetil, karakteristik tanpa gambar dan penyebab dari pengalaman penggambaran (imagery experience).

Berbagai pihak lain juga perlu dicantumkan yang telah mengembangkan dan mempertahankan teori gambar secara memuaskan dalam menjawab berbagai kritik tersebut. Namun terlepas dari berbagai pengembangan tersebut, banyak dari diskusi filosofi dan ilmiah mengenai penggambaran dan fungsi kognitif dapat atau tidak didasarkan pada asumsi yang sering kali tidak ternyatakan (dan tidak teruji), jika ada penggambaran mental, hal itu harus melibatkan gambar internal.

Bentukan lain di mana ekspresi 'penggambaran mental' (bersama dengan berbagai sinonimnya dalam keseharian) dapat saja salah arah, bahwasannya hal tersebut cenderung mengacu hanya pada fenomena serupa-visual (quasi-visual). Terlepas dari kenyataan bahwa kebanyakan diskusi ilmiah terkait dengan penggambaran, yang terjadi di masa lampau dan masa kini, berfokus secara ekslusif hanya pada modus visual, namun pengalaman serupa-perseptual (quasi-perceptual) pada modus sensorik lainnya juga sama nyatanya dan sering kali seawam dan sama pentingnya ditinjau dari aspek psikologis.

\section{9 | Pelati han Karakter Buil ding Dan Mental Imagery} Nurul Ihsan ${ }^{1}$, Syahrastani ${ }^{2}$, Ali As mi ${ }^{3}$ 


\section{JURNAL BERKARYA PENGABDIAN PADA MASYALIATSAJ \\ Volume 1, No.1, 2019 \\ ISSN — (Print) I

Open Access | http:jba.ppj.unp.acild

Para peneliti bidang kognitif kontemporer secara umum mengenali hal ini, dan studi yang menarik dari penggambaran audio (auditory imagery), penggambaran kinestetik (kinaesthetic (or motor) imagery), penggambaran aroma (olfactory imagery), penggambaran sentuhan (haptic (touch) imagery) dan lainnya, dapat dijumpai pada beberapa literatur ilmiah terkini. Namun berbagai studi tersebut masih lebih sedikit secara kuantitas dibandingkan studi yang terkait dengan penggambaran secara visual. Namun demikian 'penggambaran' telah menjadi terminologi yang diterima, diantara ilmuwan kognitif, untuk pengalaman serupa-perseptual pada berbagai modus pengindraan (atau kombinasi di antara berbagai modus pengindraan).

\section{DAFTAR PUSTAKA}

Asnaldi, A. (2016). HUBUNGAN PENDEKATAN LATIHAN MASSED PRACTICE DAN DISTRIBUTED PRACTICE TERHADAP KETEPATAN PUKULAN LOB PEMAIN BULUTANGKIS. Jurnal Menssana, 1(2), 20-26.

https://adityaramadhanim.word press.com/2013/06/22/character-building/ https://yudhistira31.wordpress.com/2009/11/10/mental-imagery/

Paivio, A. (1986). Mental Representations: A Dual Coding Approach. New York: Oxford University Press.

Pylyshyn, Z.W. (2002). Mental Imagery: In search of a theory. Behavioral and Brain Sciences.

Slezak, P. (1995). The "Philosophical” Case Against Visual Imagery. In P. Slezak,

Thomas, N.J.T. (1999). Are Theories of Imagery Theories of Imagination? An Active Perception Approach to Conscious Mental Content.

Tye, M. (1991). The Imagery Debate. Cambridge, MA: MIT Press. 